\title{
Pressure wire compared to microcatheter sensing for coronary fractional flow reserve: the PERFORM study
}

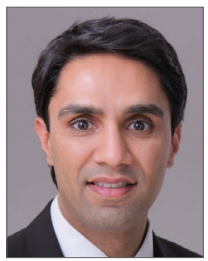

Ziad A. Alii ${ }^{1,2 *}$, MD, DPhil; Yasir Parviz ${ }^{1}$, MBBS; Matthew Brinkman ${ }^{1}$, MS; Mitsuaki Matsumura ${ }^{2}, \mathrm{BS}$; Björn Redfors², MD, PhD; David A. Brogno르, MD; Maria D. Corral2 ${ }^{2}, \mathrm{MD}, \mathrm{MS}$; Khady N. Fall ${ }^{1}, \mathrm{MD}, \mathrm{MPH}$; Gary S. Mintz², MD; Gregg W. Stone ${ }^{1,2}$, MD; Akiko Maehara ${ }^{1,2}$, MD; Allen Jeremias ${ }^{2,3}$, MD, MSc; Ajay J. Kirtane ${ }^{1,2}$, MD, SM

1. NewYork-Presbyterian Hospital/Columbia University Medical Center, New York, NY, USA; 2. Clinical Trials Center, Cardiovascular Research Foundation, New York, NY, USA; 3. St. Francis Hospital, Roslyn, New York, NY, USA

\section{KEYWORDS}

- fractional flow

reserve

- percutaneous

coronary

intervention

- stable angina

\section{Abstract}

Aims: Among technologies used to assess FFR, a monorail, sensor-tipped micro pressure catheter (PC) may be advantageous for delivery and re-assessment. We sought to determine whether the larger cross-sectional area of the PC influences FFR measurements compared to the pressure wire.

Methods and results: PERFORM was a single-centre, prospective study designed to determine the precision and accuracy of the PC compared with the pressure wire (PW) for measurement of FFR. Eligible patients had native coronary artery target lesions with visually estimated diameter stenosis of $40-90 \%$. The independently adjudicated primary endpoint was the difference in hyperaemic PW-determined minimal FFR with and without the PC distal to the stenosis. Seventy-four patients (95 lesions) were prospectively analysed between December 2015 and December 2016. Median hyperaemic FFR was 0.84 (IQR 0.78, 0.89) with the PW and 0.79 (IQR $0.73,0.85$ ) with the PC distal to the stenosis $(\mathrm{p}<0.001)$. Such differences led to clinical discordance, whereby the PC decreased the hyperaemic PW-determined FFR from $>0.80$ to $\leq 0.80$ in 17 of 95 measurements (19\%). Median resting $\mathrm{Pd} / \mathrm{Pa}$ was lower following introduction of the PC compared with the $\mathrm{PW}$ alone ( 0.93 [IQR $0.90,0.97$ ] versus 0.90 [IQR $0.86,0.95], \mathrm{p}<0.001)$. Median pressure drift was not different between the PW and the PC $(0.01$ [IQR $-0.01,0.05]$ versus 0.01 [IQR $0.00,0.02]$, $\mathrm{p}=0.38$ ).

Conclusions: Introduction of the PC reduced both hyperaemic FFR and resting Pd/Pa compared with the PW alone, leading to re-classifying physiological significance to below the clinical threshold in one out of five assessments. ClinicalTrials.gov Identifier: NCT02648230

*Corresponding author: Columbia University Medical Center, Cardiovascular Research Foundation, 1700 Broadway, 9th Floor, 


\section{Abbreviations}

FFR fractional flow reserve

IQR interquartile range

MLD minimum lumen diameter

$\mathrm{Pa}$ aortic pressure

PC pressure catheter

Pd distal pressure

PW pressure wire

QCA quantitative coronary angiography

RVD reference vessel diameter

\section{Introduction}

Fractional flow reserve (FFR) measurements in randomised clinical outcomes trials were made using a 0.014 " coronary hypotube with a piezo-resistive sensor near its tip ${ }^{1-3}$. However, the presence of electrical connections, and more recently optical fibre, within the shaft of these "wires" limits their torqueability in comparison to workhorse wires. A new FFR technology with an optical pressure sensor mounted at the tip of a monorail microcatheter (Navvus $^{\circledR}$; ACIST Medical Systems, Eden Prairie, MN, USA) has been developed to counter some of the limitations of the wirebased FFR measurement. While a microcatheter system facilitates multiple advancement and withdrawal over the operator's guidewire of choice, the larger diameter of the catheter may also influence coronary haemodynamics across the target lesion. The degree to which this may occur in practice is unknown.

The PrEssure wiRe Compared to Microcatheter-based Sensing Technology For the Evaluation of FFR Measurements (PERFORM) study was designed to determine the precision and accuracy of the Navvus pressure catheter (PC) compared with the pressure wire (PW) among an unselected group of patients undergoing FFR assessment for routine clinical indications.

\section{Methods STUDY DESIGN}

PERFORM was a prospective, single-centre study conducted at Columbia University Medical Center (New York, NY, USA) comparing the PW (Aeris ${ }^{\text {TM}}$; St. Jude Medical, St. Paul, MN, USA) and the PC (Navvus). The institutional review board approved the study protocol. The trial was registered at ClinicalTrials.gov: NCT02648230.

\section{PARTICIPANTS}

Patients undergoing coronary angiography based on clinical indication were considered for enrolment. Eligible patients had one or more target lesions located in a native coronary artery with visually estimated diameter stenosis of $40-90 \%$ and planned use of FFR for clinical decision making ${ }^{4}$. Left main or ostial right coronary artery stenosis, bypass graft stenoses, and chronic total occlusions were excluded.

\section{PROCEDURES}

Coronary angiography was performed via femoral or radial access, and anticoagulation, dual antiplatelet therapy and other medications were administered per local standard of care. A minimum 6 Fr guiding catheter was used.

Following angiography, performed in a view that would allow optimal quantitative coronary angiography (QCA), physiological assessments were performed (Figure 1). Briefly, the PC was loaded onto the PW, and the aortic pressure transducer, PC, and PW all equilibrated to zero pressure outside of the body. With the PC used as an introducer, the PW alone was advanced to the aorto-ostial junction where PW equalisation was performed after ensuring the presence of an appropriate aortic waveform, with guide disengagement performed if necessary. The PW was then advanced across the lesion with the sensor located at least $3 \mathrm{~cm}$ distal to the lesion and preferably in the distal third of the artery. Following administration of intracoronary nitroglycerine and saline flush, the guide catheter was disengaged, the position of the PW was recorded on cine angiography, and the lowest basal distal pressure/aortic pressure $(\mathrm{Pd} / \mathrm{Pa})$ was recorded. The preloaded $\mathrm{PC}$ was then advanced from outside the body to the aorto-ostial junction where PC equalisation was performed, again ensuring the presence of the appropriate aortic waveform. The PC was then advanced just proximal to the $\mathrm{PW}$ sensor, and the lowest basal $\mathrm{Pd} / \mathrm{Pa}$ of both the PC and PW was recorded simultaneously. To induce hyperaemia, intravenous adenosine was infused at $140 \mu \mathrm{g} / \mathrm{kg} / \mathrm{min}$. At maximal hyperaemia, the FFR was recorded on both the PW and the PC. The PC was then slowly pulled back, making note of pressure step-ups across the lesion, and the PC drift was recorded at the aorto-ostial junction. Subsequently, the PC was completely removed, and the FFR was recorded again with the PW alone. The PW was then slowly pulled back, making note of pressure step-ups across the lesion, and the pressure again recorded at the aorto-ostial junction. $\mathrm{Pd} / \mathrm{Pa}, \mathrm{FFR}$, and pressure drift of each device were also recorded in real time using timestamped still photography. Revascularisation was guided by hyperaemic FFR measured by the PW alone.

\begin{tabular}{|l|l|l|l|l|l|}
\hline Pre-procedure & Resting & Hyperaemia (iv adenosine) & Pullback/Pressure drift \\
\hline \begin{tabular}{|l|l|l|l|}
\hline 1) PC mounted onto PW \\
2) Aorta, PC, PW zero calibration
\end{tabular} & \begin{tabular}{llll} 
3) Resting Pd/Pa PW & 5) Hyperaemic FFR PW+PC & 6) Pressure drift PC \\
\hline
\end{tabular}
\end{tabular}

Figure 1. Protocol for physiologic assessment using a pressure wire and a pressure catheter. FFR: fractional flow reserve; IV: intravenous; $P C$ : pressure catheter; $P W$ : pressure wire 


\section{OUTCOMES}

The primary endpoint of the study was the difference in hyperaemic PW-determined minimal FFR with and without the presence of the PC distal to the stenoses. Secondary endpoints included device success (the ability to cross the lesion and record a hyperaemic FFR), the difference in $\mathrm{PW}$-determined resting $\mathrm{Pd} / \mathrm{Pa}$ with and without the $\mathrm{PC}$ distal to the stenosis, PW and PC pressure drift, and discordance in physiological significance (hyperaemic FFR $\leq 0.80$ by one modality versus $>0.80$ with the other modality and hyperaemic FFR $\leq 0.75$ by one modality versus $>0.80$ with the other modality). Other outcomes assessed were the proportion of lesions with a mean hyperaemic FFR difference $\geq 0.05$ and $\geq 0.10$, and a sensitivity analysis for resting $\mathrm{Pd} / \mathrm{Pa}$ and hyperaemic FFR comparing measurements made using the PW versus the $\mathrm{PC}$ when both devices were in the distal coronary artery.

\section{DATA ANALYSIS}

Primary and secondary imaging and physiology endpoints were independently performed in the angiography and physiology core laboratories at the Cardiovascular Research Foundation (New York, NY, USA). Offline QCA analyses to determine percentage diameter stenosis, reference artery diameter, and lesion level characteristics were performed by an independent core lab (Cardiovascular Research Foundation) using automated software (QAngio; Medis, Leiden, the Netherlands). Haemodynamic data were analysed by an independent physiology core lab (Cardiovascular Research Foundation). Tracing from the PW and the PC were scrambled in the core laboratory such that measurements did not undergo paired analysis, avoiding bias.

\section{STATISTICAL ANALYSIS}

The sample size was calculated assuming a difference of 0.02 between PC- and PW-determined FFR with a standard deviation of $0.065^{5,6}$. At an $\alpha$ of 0.025 (one-sided), 85 lesions would be required to reject the null hypothesis that there was no difference between PC- and PW-measured FFR with $80 \%$ power. Normal distribution of parameters was assessed using the Kolmogorov-Smirnov test, and homogeneity of variance was assessed using Levene's test. Continuous values were summarised using median and interquartile range (IQR), and differences were compared using the MannWhitney $U$ test. Systematic errors of measurement induced by the PC were assessed using Pearson correlation and Bland-Altman analysis. The univariate association between the PW and PC difference in measurements $(\triangle \mathrm{FFR})$ and patient or lesion characteristics was assessed using the Student's t-test (binary parameters) or Pearson correlation (continuous parameters). The adjusted association between the $\triangle F F R$ and patient and lesion characteristics was determined using multivariable linear regression. P-values $<0.05$ were considered statistically significant. All analyses were performed with SAS version 9.4 (SAS Institute, Cary, NC, USA).

\section{Results}

\section{PATIENTS AND PROCEDURES}

Between December 2015 and December 2016, 74 patients with 95 lesions had successful PW measurements and were enrolled in the study. Patient data and angiographic lesion characteristics are presented in Table 1.

\section{STUDY ENDPOINTS}

Device success in crossing the lesion was $100 \%$ with the PW and $95 \%$ with the PC $(\mathrm{p}=0.02)$. FFR was available with both the PW and the $\mathrm{PC}$ for 89 lesions (94\%), and resting $\mathrm{Pd} / \mathrm{Pa}$ was available with both the PW and PC for 88 lesions (93\%). Resting $\mathrm{Pd} / \mathrm{Pa}$ measured on the PW decreased significantly from 0.93 (IQR 0.90 , 0.97 ) to 0.90 (IQR 0.86, 0.95), following advancement of the PC distal to the stenosis $(\mathrm{p}<0.001)$ (Table 2). While the PW and PC assessments of resting $\mathrm{Pd} / \mathrm{Pa}$ were closely correlated (Figure 2A), the PC led to overestimation of the pressure gradient. BlandAltman analysis did not identify systematic differences between $\mathrm{PW}$ and $\mathrm{PC}$ measurements of the resting $\mathrm{Pd} / \mathrm{Pa}$ (Figure 2B). The distribution of the differences in $\mathrm{Pd} / \mathrm{Pa}$ is shown in Figure 2C.

Table 1. Patient and procedural characteristics.

Patient-level characteristics ( $\mathrm{N}=74)$

\begin{tabular}{|l|c|}
\hline Age, years & $64 \pm 11$ \\
\hline Male & $54(73)$ \\
\hline Weight, kg & $83 \pm 18$ \\
\hline Height, cm & $171 \pm 10$ \\
\hline Diabetes & $53(72)$ \\
\hline Hypertension & $71(96)$ \\
\hline Hypercholesterolaemia & $73(99)$ \\
\hline Former smoker & $38(51)$ \\
\hline Current smoker & $12(16)$ \\
\hline History of heart failure & $43(58)$ \\
\hline Ejection fraction, \% & $55 \pm 13$ \\
\hline
\end{tabular}

Lesion-level characteristics ( $N=95)$

\begin{tabular}{|l|l|c|}
\hline \multirow{2}{*}{ Target vessel } & Left anterior descending & $47(49)$ \\
\cline { 2 - 3 } & Left circumflex & $23(24)$ \\
\cline { 2 - 3 } & Right & $25(26)$ \\
\hline Eccentric lesion & $64(67)$ \\
\hline Thrombus & $1(1)$ \\
\hline Tortuosity & $32(34)$ \\
\hline Calcification & $51(54)$ \\
\hline Aneurysmal lesion & $5(5)$ \\
\hline Ectasia present & $12(13)$ \\
\hline Bifurcation & $21(22)$ \\
\hline Interpolated reference vessel diameter, mm & $2.84 \pm 0.58$ \\
\hline Distal reference vessel diameter, mm & $2.66 \pm 0.58$ \\
\hline In-segment minimum lumen diameter, mm & $1.61 \pm 0.48$ \\
\hline $\begin{array}{l}\text { Diameter stenosis (by quantitative coronary } \\
\text { angiography), \% }\end{array}$ & $44 \pm 10$ \\
\hline Diameter stenosis (visual), \% & $66 \pm 10$ \\
\hline Lesion length, mm & $12.2 \pm 7.3$ \\
\hline Lesion angle, ${ }^{\circ}$ & $26.5 \pm 10.3$ \\
\hline Values are mean \pm standard deviation or $\mathrm{n}(\%)$. & \\
\hline
\end{tabular}



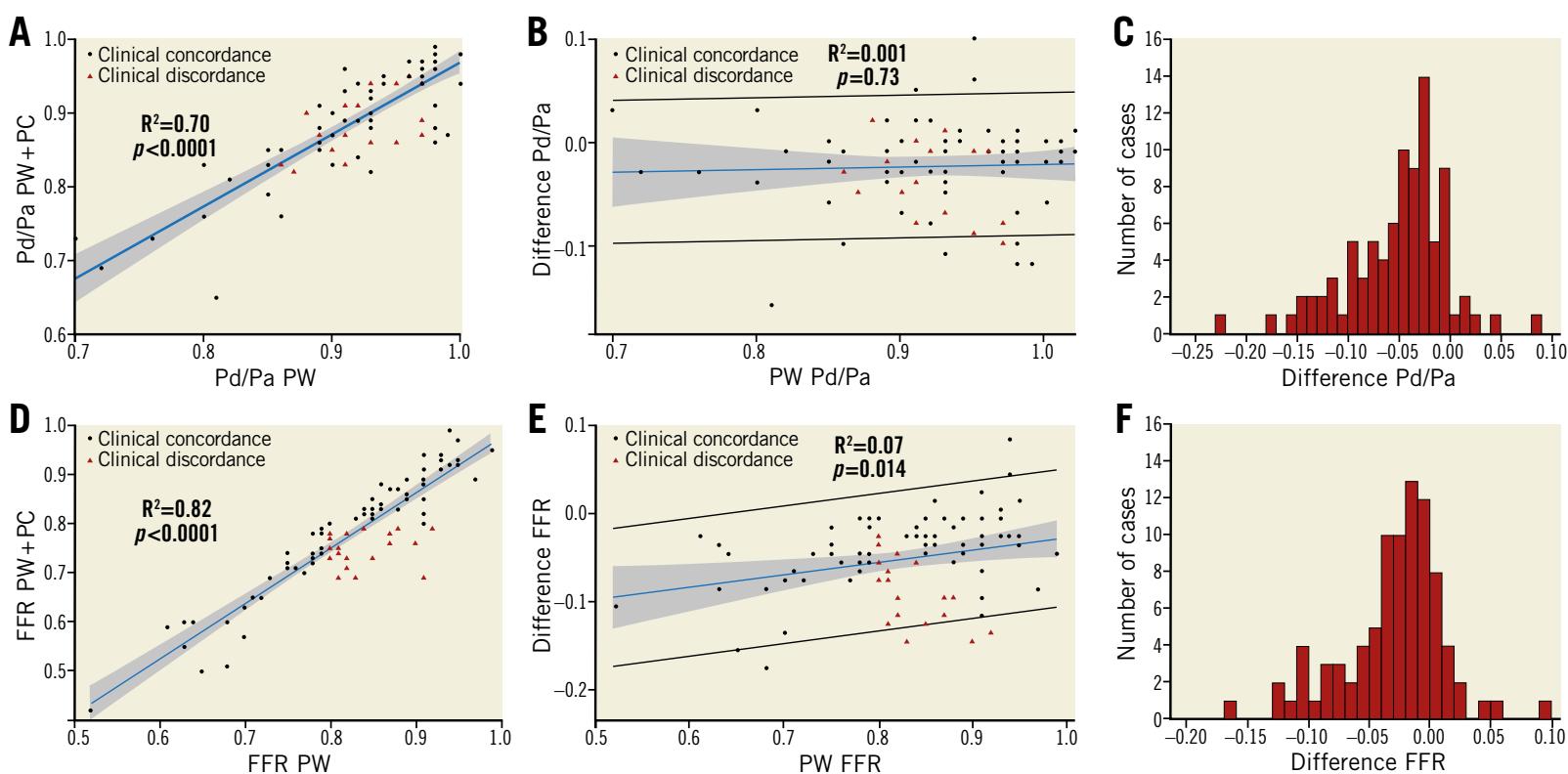

Figure 2. Correlation between resting Pd/Pa and hyperaemic fractional flow reserve between pressure catheter and pressure wire. Correlation between the pressure catheter $(P C)$ and pressure wire $(P W)(A)$ and Bland-Altman analysis of agreement (B) for resting Pd/Pa. Distribution of the difference in $P d / P a$ between $P C$ and $P W(C)$. Correlation between the $P C$ and $P W(D)$ and Bland-Altman analysis of agreement $(E)$ for hyperaemic fractional flow reserve (FFR). Distribution of the difference in FFR between PC and PW (F).

Following the introduction of the PC distal to the target lesion, hyperaemic FFR measured on the PW decreased significantly from $0.84(\mathrm{IQR} 0.78,0.89)$ to $0.79(\mathrm{IQR} 0.73,0.85)(\mathrm{p}<0.001)$ (Table 2). While the PW and PC assessments of hyperaemic FFR were well correlated $(\mathrm{R} 2=0.82, \mathrm{p}<0.0001)$ (Figure 2D), introduction of the PC distal to the stenosis led to overestimation of the severity of the pressure gradient. Moreover, the difference between PW and PC measurements increased with decreasing FFR values (Figure 2E), indicating that FFR overestimation by the PC occurs more frequently in more severe lesions. The introduction of the PC resulted in a decrease in FFR compared with the PW alone by $\geq 0.10$ in $13(15 \%)$ lesions and by $\geq 0.05$ in 35 (39\%) lesions. These differences led to discordance in ascribing physiologic significance in a number of lesions, with the PC measuring FFR $\leq 0.80$ in 17 lesions (19\%) for which the FFR measured by the PW was $>0.80$ (Table 2), and with the PC measuring FFR $\leq 0.75$ in eight lesions $(9 \%)$ for which the $\mathrm{PW}$ was $>0.80$. There were no instances of the PW measuring FFR $\leq 0.80$ and the PC $>0.80$. The distribution of the differences in FFR is shown in Figure 2F.

Sensitivity analyses identified no difference in resting $\mathrm{Pd} / \mathrm{Pa}$ (0.90 [IQR 0.86, 0.95] versus 0.91 [IQR 0.87, 0.96], $\mathrm{p}=0.054)$ or hyperaemic FFR $(0.79$ [IQR $0.73,0.85$ ] versus 0.80 [IQR 0.73 , 0.86 ], $\mathrm{p}=0.44$ ) measured by the $\mathrm{PW}$ or $\mathrm{PC}$ when both devices were simultaneously in the distal coronary circulation. Pressure drift was not different between the PC and the PW (0.01 [IQR - 0.01 , 0.05] versus 0.01 [IQR $0.00,0.02$ ], $\mathrm{p}=0.38$ ).

Among patients with $\triangle F F R$ (difference between FFR measured by $\mathrm{PC}$ and $\mathrm{PW}$ ), lesion location in the right coronary artery, inter-
Table 2. Physiological parameters.

\begin{tabular}{|l|c|c|c|}
\hline \multicolumn{1}{|c|}{ Parameter } & $\begin{array}{c}\text { Pressure } \\
\text { wire }\end{array}$ & $\begin{array}{c}\text { Pressure } \\
\text { catheter }\end{array}$ & $\boldsymbol{p}$-value \\
\hline FFR & $\begin{array}{c}0.84 \\
{[0.78,0.89]}\end{array}$ & $\begin{array}{c}0.79 \\
{[0.73,0.85]}\end{array}$ & $<0.001$ \\
\hline $\begin{array}{l}\text { Clinically discordant (FFR from } \\
>0.80 \text { to } \leq 0.80)\end{array}$ & - & $17(19)$ & $<0.001$ \\
\hline FFR underestimated by $\geq 0.05, \% *$ & $2(2)$ & $35(39)$ & $<0.001$ \\
\hline FFR underestimated by $\geq 0.10, \% *$ & $0(0)$ & $13(15)$ & $<0.001$ \\
\hline Pd/Pa & $\begin{array}{c}0.93 \\
{[0.90,0.97]}\end{array}$ & $\begin{array}{c}0.90 \\
{[0.86,0.95]}\end{array}$ & $<0.001$ \\
\hline Pressure drift & $\begin{array}{c}0.01 \\
{[-0.01,0.05]}\end{array}$ & $\begin{array}{c}0.01 \\
{[0.00,0.02]}\end{array}$ & 0.38 \\
\hline
\end{tabular}

*Versus the other device. Values are median (interquartile range). FFR: fractional flow reserve; Pa: aortic pressure; Pd: distal pressure

polated reference vessel diameter (RVD), distal RVD, in-segment minimum lumen diameter (MLD), and lesion length were significantly associated with the $\triangle F F R$ in univariate analyses (Table 3). Discordance between PW and PC measurements was observed more often in vessels with small distal RVD and longer lesion length with differences pronounced in different ranges of FFR values (Figure 3). In multivariable analyses only distal RVD and lesion length were identified as independent predictors of $\triangle F F R$ (Table 4).

\section{Discussion}

PERFORM was a direct comparison of the PW and the PC for physiologic assessment of moderate coronary artery stenosis, which aimed to determine whether the larger cross-sectional area of the 
Table 3. Univariate associations between patient/lesion characteristics and the difference in fractional flow reserve measured with the pressure wire versus pressure catheter.

\begin{tabular}{|c|c|c|c|c|}
\hline \multicolumn{4}{|c|}{ Observed difference in fractional flow reserve according to the presence versus absence of a characteristic } & \\
\hline \multicolumn{2}{|c|}{ Patient/lesion characteristic } & Characteristic present & Characteristic absent & p-value \\
\hline \multicolumn{2}{|c|}{ Male (men vs. women) } & $-0.03(-0.05,-0.02)$ & $-0.03(-0.08,-0.01)$ & 0.63 \\
\hline \multicolumn{2}{|c|}{ Diabetes (yes vs. no) } & $-0.03(-0.08,0.00)$ & $-0.03(-0.07,-0.02)$ & 0.46 \\
\hline \multicolumn{2}{|c|}{ Hypertension (yes vs. no) } & $-0.03(-0.13,-0.02)$ & $-0.03(-0.06,-0.01)$ & 0.16 \\
\hline \multicolumn{2}{|c|}{ History of heart failure (yes vs. no) } & $-0.04(-0.09,-0.02)$ & $-0.03(-0.05,0.00)$ & 0.12 \\
\hline \multicolumn{2}{|c|}{ Previous cerebrovascular accident (yes vs. no) } & $-0.06(-0.09,-0.02)$ & $-0.03(-0.05,0.00)$ & 0.053 \\
\hline \multicolumn{2}{|c|}{ Former smoker (yes vs. no) } & $-0.03(-0.05,-0.01)$ & $-0.04(-0.08,-0.02)$ & 0.40 \\
\hline \multicolumn{2}{|c|}{ Current smoker (yes vs. no) } & $-0.03(-0.08,-0.02)$ & $-0.03(-0.04,-0.01)$ & 0.43 \\
\hline \multicolumn{2}{|c|}{ Non-smoker (yes vs. no) } & $-0.03(-0.06,-0.02)$ & $-0.03(-0.11,-0.01)$ & 0.80 \\
\hline \multirow[t]{3}{*}{ Target vessel } & LAD (yes vs. no) & $-0.03(-0.06,-0.02)$ & $-0.04(-0.08,-0.02)$ & 0.35 \\
\hline & LCx (yes vs. no) & $-0.03(-0.05,-0.02)$ & $-0.04(-0.09,-0.02)$ & 0.30 \\
\hline & RCA (yes vs. no) & $-0.04(-0.08,-0.02)$ & $-0.03(-0.04,0.00)$ & 0.033 \\
\hline \multicolumn{2}{|c|}{ Eccentric lesion (yes vs. no) } & $-0.03(-0.06,-0.02)$ & $-0.04(-0.08,-0.02)$ & 0.32 \\
\hline \multicolumn{2}{|c|}{ Tortuosity (yes vs. no) } & $-0.04(-0.06,-0.02)$ & $-0.04(-0.09,-0.02)$ & 0.23 \\
\hline \multicolumn{2}{|c|}{ Calcification (yes vs. no) } & $-0.04(-0.07,-0.02)$ & $-0.04(-0.08,-0.02)$ & 0.74 \\
\hline \multicolumn{2}{|c|}{ Ulcerated lesion (yes vs. no) } & $-0.04(-0.08,-0.02)$ & $-0.07(-0.08,-0.03)$ & 0.46 \\
\hline \multicolumn{2}{|c|}{ Aneurysmal lesion (yes vs. no) } & $-0.04(-0.07,-0.02)$ & $-0.04(-0.04,-0.02)$ & 0.93 \\
\hline \multicolumn{2}{|c|}{ Ectasia present (yes vs. no) } & $-0.04(-0.07,-0.02)$ & $-0.05(-0.08,-0.02)$ & 0.69 \\
\hline \multicolumn{2}{|c|}{ Bifurcation (yes vs. no) } & $-0.04(-0.07,-0.02)$ & $-0.04(-0.09,-0.01)$ & 0.88 \\
\hline \multicolumn{5}{|c|}{ Correlation between continuous variables and the observed difference in fractional flow reserve } \\
\hline \multirow{2}{*}{\multicolumn{2}{|c|}{ Patient/lesion characteristic }} & \multicolumn{2}{|c|}{$\Delta$ Fractional flow reserve } & \multirow{2}{*}{$p$-value } \\
\hline & & Mean \pm standard deviation & Correlation coefficient & \\
\hline \multicolumn{2}{|l|}{ Age, years } & $63.90 \pm 10.66(89)$ & $0.10(-0.11,0.30)$ & 0.36 \\
\hline \multicolumn{2}{|l|}{ Weight, kg } & $81.73 \pm 18.07(89)$ & $0.11(-0.11,0.31)$ & 0.33 \\
\hline \multicolumn{2}{|l|}{ Height, $\mathrm{cm}$} & $170.18 \pm 9.55(89)$ & $0.10(-0.11,0.30)$ & 0.35 \\
\hline \multicolumn{2}{|c|}{ Ejection fraction, \% } & $55.10 \pm 13.23(60)$ & $0.14(-0.12,0.38)$ & 0.30 \\
\hline \multicolumn{2}{|c|}{ Interpolated reference vessel diameter, $\mathrm{mm}$} & $2.84 \pm 0.59(89)$ & $0.31(0.11,0.49)$ & 0.003 \\
\hline \multicolumn{2}{|c|}{ Distal reference vessel diameter, $\mathrm{mm}$} & $2.66 \pm 0.59(89)$ & $0.35(0.16,0.52)$ & $<0.001$ \\
\hline In-segment m & diameter, mm & $1.61 \pm 0.50(89)$ & $0.27(0.06,0.45)$ & 0.01 \\
\hline Diameter ster & & $43.92 \pm 10.45(89)$ & $-0.08(-0.29,0.13)$ & 0.43 \\
\hline Diameter ster & & $65.84 \pm 10.34(89)$ & $-0.16(-0.36,0.05)$ & 0.13 \\
\hline Lesion length & & $12.10 \pm 7.22(89)$ & $-0.23(-0.42,-0.03)$ & 0.027 \\
\hline Lesion angle, & & $26.47 \pm 10.20(89)$ & $-0.09(-0.29,0.13)$ & 0.43 \\
\hline
\end{tabular}

Values are median (interquartile range) or mean \pm standard deviation $(\mathrm{N})$ and correlation coefficient ( $95 \%$ confidence interval). LAD: left anterior descending coronary artery; LCx: left circumflex coronary artery; QCA: quantitative coronary angiography; RCA: right coronary artery
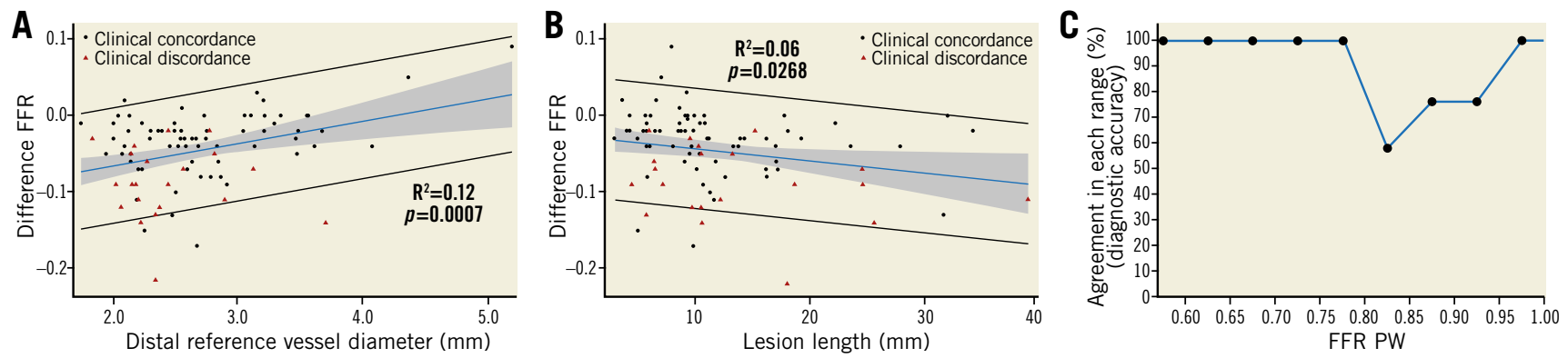

Figure 3. Relationship between $\triangle F F R$ and distal reference vessel diameter (A), lesion length (B) and agreement by FFR range (C). FFR: fractional flow reserve; PC: pressure catheter; PW: pressure wire 
Table 4. Independent predictors of $\Delta F F R$ measured with the pressure catheter versus pressure wire.

\begin{tabular}{|l|c|l|l|}
\hline \multicolumn{1}{|c|}{ Variable } & $\begin{array}{c}\text { Adjusted difference } \\
\text { (per 0.01 point } \\
\text { difference) }\end{array}$ & $\begin{array}{c}\text { 95\% confidence } \\
\text { interval }\end{array}$ & p-value \\
\hline $\begin{array}{l}\text { Distal RVD } \\
\text { (per 0.1 mm) }\end{array}$ & 0.42 & 0.009 to 0.83 & 0.045 \\
\hline $\begin{array}{l}\text { In-segment MLD } \\
\text { (per 0.1 mm) }\end{array}$ & -0.26 & -0.94 to 0.42 & 0.45 \\
\hline $\begin{array}{l}\text { Diameter stenosis } \\
\text { (visual, \%) }\end{array}$ & -0.07 & -0.27 to 0.13 & 0.51 \\
\hline $\begin{array}{l}\text { Lesion length } \\
\text { (per 1 mm) }\end{array}$ & -0.13 & -0.26 to 0.00 & 0.048 \\
\hline
\end{tabular}

MLD: minimum lumen diameter; RVD: reference vessel diameter

PC influences translesional pressure measurement compared with PW alone. We report a number of clinically relevant findings. First, while the PW was successful in crossing the target lesion and providing physiological measurements in all cases, device success for the PC was lower. Second, introduction of the PC distal to the target lesion significantly reduced both the resting $\mathrm{Pd} / \mathrm{Pa}$ and the hyperaemic FFR compared with the PW. Third, pressure drift was not different between the PC and the PW. Fourth, the magnitude of change in FFR following introduction of the PC was large, reducing FFR by $\geq 0.05$ in $39 \%$ and by $\geq 0.10$ in $15 \%$ of lesions. Fifth, these differences would re-classify $19 \%$ of "negative" FFR measurements by PW (FFR >0.80) to "positive" measurements (FFR $\leq 0.80)$ with the $\mathrm{PC}$, thus representing a false positive frequency of approximately one in five, which may adversely impact on clinical decision making. Finally, multivariable regression identified smaller distal RVD as an independent predictor of the mean difference in FFR.

The PC may be delivered over a conventional flexible guidewire, aiding delivery through significant tortuosity and into angulated side branches and distal vessels. The rapid exchange design offers the advantage of performing repeated assessment of the FFR to determine the physiological significance of tandem lesions after treatment of a single stenosis ${ }^{7}$, where one lesion may be the culprit lesion. As data accumulate suggesting the prognostic significance of post-PCI $\mathrm{FFR}^{8,9}$, the $\mathrm{PC}$ also holds a significant advantage in this respect, negating the need for re-wiring the vessel with the FFR wire or pulling back the FFR wire for re-equalisation following stenting. Nevertheless, in its current design, the PC has a larger cross-sectional profile ( 0.022 " circular diameter and maximum diameter of 0.036 " at the site of the pressure sensor) compared with the PW (0.014" circular diameter). In keeping with the central premise of FFR measurement, the larger catheter cross-sectional area artificially increases the stenosis severity and could impact on coronary haemodynamics. Indeed, previous in vitro studies have suggested this possibility not only for a monorail catheter ${ }^{10}$ but also in the simultaneous presence of two guidewires ${ }^{11}$. The present study confirms that the PC impacts on FFR measurements in the clinical setting. Furthermore, despite the theoretical benefits of improved deliverability, the larger catheter cross-sectional area may in fact impede delivery. We found that lesion crossability was significantly lower for the PC compared to the PW, as have other recent studies that confirm lower device success for the $\mathrm{PC}^{12-14}$. Of the five lesions that could not be crossed in our study, one was due to excessive tortuosity, one due to moderate calcification, two due to a combination of the two, and one due to acute angle at the origin of a large culprit vessel diagonal branch. Taken together, deliverability is not improved for the PC compared to the PW.

The ACCESS-NZ study examined 50 intermediate coronary lesions, excluding vessels with visually estimated diameter $<2.5 \mathrm{~mm}^{15}$. This analysis demonstrated a reduction in FFR from $0.81 \pm 0.11$ with the PW alone to $0.79 \pm 0.12$ with the Navvus PC across the stenosis. Limitations of this study were the small sample size, lack of QCA, and skewed drift values reported as means rather than medians. The IMPACT study included assessment of 28 stenoses, also showing a reduction in FFR after introduction of the Navvus PC $(0.82 \pm 0.07)$ compared with PW-only assessment $(0.86 \pm 0.06)^{16}$. Although the results of this trial support findings of the current study, the small sample size, intracoronary-only administration of adenosine (limiting assessment of drift), and small number of FFR values below the ischaemic threshold were limitations of this study.

Recently, two other studies evaluated the effect of the PC on hyperaemic FFR measurement. The ACIST-FFR study evaluated 210 patients in whom 169 paired measurements were performed. The authors reported a mean bias introduced by the PC of -0.03 (95\% CI: $-0.037,-0.013)$ and a diagnostic agreement of $81 \%(95 \%$ CI: $75 \%, 87 \%$ ). Importantly, using their definition of clinical discordance where the difference between PC and PW crossed the grey zone from 0.75 to 0.80 , only $2.9 \%$ of patients could have been potentially overtreated. In multivariate analysis, only FFR measured by the PC was independently associated with a bias. The authors concluded that the clinical impact of these findings was probably minimal. While ACIST-FFR is the largest study comparing the PC to the PW, the exclusion of $20 \%$ of tracings due to suboptimal FFR measurement (compared to none in our study, measured at the same core laboratory), the repeated dose of adenosine to measure FFR with and without the PC (which itself has a mean measurement difference of $0.022 \pm 0.020)^{6}$, and the exclusion of clinical discordance across the established cut-point of 0.80 are limitations. Another study by Pouillot et al ${ }^{12}$ examined 88 stenoses in 99 consecutive patients and found that introduction of the PC led to a mean decrease in FFR of $-0.03 \pm 0.05$. Moreover, using a threshold of 0.80 for FFR, they identified clinical discordance in $23 \%$ of lesions and $23 \%$ of patients. The marked similarity between the results reported by Pouillot et $\mathrm{al}^{12}$ and our findings substantiate that introduction of the PC impacts both on the measurement of FFR and also potentially on clinical decision making.

In the current study, the finding of a clinically relevant effect of the PC on measured FFR raises a number of clinically relevant questions. Can a correction factor be applied to the pressure catheter such that the difference between modalities is negated? Our data suggest that this may not be possible, as significant variability between 
the PW and the PC, especially in values around the 0.8 ischaemia threshold (Figure 2B), exists. We did, however, identify a systematic and proportional difference in the FFR, finding a greater difference between devices the lower the FFR values were (Figure 2B). Univariate analysis identified a number of factors associated with the $\triangle F F R$ between devices. Nonetheless, in multivariable analysis, only distal RVD and lesion length were identified as independent predictors of $\triangle F F R$. These data suggest that operators need to pay close attention to placement of the PC during physiological assessment, perhaps placing the PC distal to the stenosis, but not in the very distal coronary artery, or interpreting the PC-based FFR measurements in smaller vessels with caution.

\section{Study limitations}

Our study has a number of important limitations. First, our study was conducted in a single centre with significant experience in physiological assessment using FFR, which may limit its generalisability. Nevertheless, no pressure tracings were rejected by the physiology core laboratory, highlighting a potential advantage of a single centre where both physician training and trial monitoring are closely regulated and uniform. Second, our study was not randomised. The IMPACT study randomised physiological assessment by PC or PW, changing the order of use of the devices by random allocation ${ }^{16}$; however, measurements in our study were performed during a single administration of intravenous adenosine as an infusion and thus may be less prone to the error introduced by intracoronary bolus adenosine administration in the IMPACT study $^{16}$. Third, a larger sample size may have been able to provide greater power to detect specific patient or lesion characteristics associated with the $\triangle$ FFR. Fourth, we compared the PC to a specific PW from a single manufacturer. Although similar findings between the PC and other PWs may be inferred, our study can neither confirm nor refute this possibility. Finally, a new iteration of the PC is available with $33 \%$ less cross-sectional area, probably impacting on our findings.

\section{Conclusions}

In conclusion, introduction of the larger cross-sectional area PC reduced device success and both resting $\mathrm{Pd} / \mathrm{Pa}$ and hyperaemic FFR compared with the PW, with no difference in drift. Compared with the PW, the PC led to re-classifying physiological significance to below the clinical threshold in one out of five assessments, particularly in vessels with small distal reference vessel diameters and long lesions, where PC measurements may be less reliable due to the larger cross-sectional profile of the PC.

\section{Impact on daily practice}

The results of the current study are consistent with others evaluating the haemodynamic effect of the larger diameter PC across intermediate coronary stenoses. While varying marginally in the magnitude of the difference, the PC does introduce a decrease in the hyperaemic FFR.

\section{Funding}

The study was designed by the investigators and supported by a grant from St. Jude Medical.

\section{Conflict of interest statement}

The authors have institutional research grant support from both St. Jude Medical and ACIST Medical Systems. Z. Ali has served as a consultant to St. Jude Medical and ACIST Medical Systems and holds grant support from St. Jude Medical and Cardiovascular Systems Inc., to Columbia University. G. Mintz has received consulting fees from ACIST, Boston Scientific, Infraredx, St. Jude, and Volcano. A. Maehara has received consulting fees from Boston Scientific and OCT Imaging Inc., and research grants from Boston Scientific and St. Jude Medical. A. Jeremias is a consultant to Philips and Abbott Vascular. A. Kirtane reports institutional grants to Columbia University and/or Cardiovascular Research Foundation from Medtronic, Boston Scientific, Abbott Vascular, Abiomed, Cardiovascular Systems Inc., CathWorks, Siemens, Philips, ReCor Medical, and Spectranetics. The other authors have no conflicts of interest to declare.

\section{References}

1. De Bruyne B, Pijls NH, Kalesan B, Barbato E, Tonino PA, Piroth Z, Jagic N, Möbius-Winkler S, Rioufol G, Witt N, Kala P, Maccarthy P, Engström T, Oldroyd KG, Mavromatis K, Manoharan G, Verlee P, Frobert O, Curzen N, Johnson JB, Jüni P, Fearon WF; FAME 2 Trial Investigators. Fractional flow reserveguided PCI versus medical therapy in stable coronary disease. N Engl J Med. 2012;367:991-1001.

2. Pijls NH, Van Schaardenburgh P, Manoharan G, Boersma E, Bech JW, Van't Veer M, Bär F, Hoorntje J, Koolen J, Wijns W, De Bruyne B. Percutaneous coronary intervention of functionally nonsignificant stenosis: 5-year follow-up of the DEFER Study. $J \mathrm{Am}$ Coll Cardiol. 2007;49:2105-11.

3. Tonino PA, De Bruyne B, Pijls NH, Siebert U, Ikeno F, van' t Veer M, Klauss V, Manoharan G, Engstrom T, Oldroyd KG, Ver Lee PN, Maccarthy PA, Fearon WF; FAME Study Investigators. Fractional flow reserve versus angiography for guiding percutaneous coronary intervention. N Engl J Med. 2009;360:213-24.

4. Tonino PA, Fearon WF, De Bruyne B, Oldroyd KG, Leesar MA, Ver Lee PN, Maccarthy PA, Van't Veer M, Pijls NH. Angiographic versus functional severity of coronary artery stenoses in the FAME study fractional flow reserve versus angiography in multivessel evaluation. J Am Coll Cardiol. 2010;55:2816-21.

5. De Bruyne B, Pijls NH, Barbato E, Bartunek J, Bech JW, Wijns W, Heyndrickx GR. Intracoronary and intravenous adenosine 5 '-triphosphate, adenosine, papaverine, and contrast medium to assess fractional flow reserve in humans. Circulation. 2003;107: 1877-83.

6. Johnson NP, Johnson DT, Kirkeeide RL, Berry C, De Bruyne B, Fearon WF, Oldroyd KG, Pijls NHJ, Gould KL. Repeatability of Fractional Flow Reserve Despite Variations in Systemic and Coronary Hemodynamics. JACC Cardiovasc Interv. 2015;8:1018-27. 
7. Daniels DV, Van't Veer M, Pijls NH, Van Der Horst A, Yong AS, De Bruyne B, Fearon WF. The impact of downstream coronary stenoses on fractional flow reserve assessment of intermediate left main disease. JACC Cardiovasc Interv. 2012;5:1021-5.

8. Rimac G, Fearon WF, De Bruyne B, Ikeno F, Matsuo H, Piroth Z, Costerousse O, Bertrand OF. Clinical value of post-percutaneous coronary intervention fractional flow reserve value: A systematic review and meta-analysis. Am Heart J. 2017; 183:1-9.

9. Agarwal SK, Kasula S, Hacioglu Y, Ahmed Z, Uretsky BF, Hakeem A. Utilizing Post-Intervention Fractional Flow Reserve to Optimize Acute Results and the Relationship to Long-Term Outcomes. JACC Cardiovasc Interv. 2016;9:1022-31.

10. Banerjee RK, Peelukhana SV, Goswami I. Influence of newly designed monorail pressure sensor catheter on coronary diagnostic parameters: an in vitro study. J Biomech. 2014;47:617-24.

11. Verberne HJ, Meuwissen M, Chamuleau SA, Verhoeff BJ, Van Eck-Smit BL, Spaan JA, Piek JJ, Siebes M. Effect of simultaneous intracoronary guidewires on the predictive accuracy of functional parameters of coronary lesion severity. Am J Physiol Heart Circ Physiol. 2007;292:H2349-55.

12. Pouillot C, Fournier S, Glasenapp J, Rambaud G, Bougrini K, Vi Fane R, Geyer C, Adjedj J. Pressure wire versus microcatheter
forFFR measurement: a head-to-head comparison. EuroIntervention. 2018;13:e1850-6.

13. Masdjedi K, Van Mieghem NM, Diletti R, Van Geuns RJ, De Jaegere P, Regar E, Zijlstra F, Van Domburg RT, Daemen J. Navvus FFR to reduce CONTRAst, Cost and radiaTion (CONTRACT); insights from a single-centre clinical and economical evaluation with the Rxi Rapid-Exchange FFR device. Int J Cardiol. 2017;233:80-4.

14. Fearon WF, Chambers JW, Seto AH, Sarembock IJ, Raveendran G, Sakarovitch C, Yang L, Desai M, Jeremias A, Price MJ; ACIST-FFR Study Investigators. ACIST-FFR Study (Assessment of Catheter-Based Interrogation and Standard Techniques for Fractional Flow Reserve Measurement). Circ Cardiovasc Interv. 2017 Dec;10(12).

15. Menon M, Jaffe W, Watson T, Webster M. Assessment of coronary fractional flow reserve using a monorail pressure catheter: the first-in-human ACCESS-NZ trial. EuroIntervention. 2015;11:257-63.

16. Wijntjens GW, Van De Hoef TP, Kraak RP, Beijk MA, Sjauw KD, Vis MM, Madera Cambero MI, Brinckman SL, Plomp J, Baan J Jr, Koch KT, Wykrzykowska JJ, Henriques JP, De Winter RJ, Piek JJ. The IMPACT Study (Influence of Sensor-Equipped Microcatheters on Coronary Hemodynamics and the Accuracy of Physiological Indices of Functional Stenosis Severity). Circ Cardiovasc Interv. 2016 Dec;9(12). 